\title{
Key Theoretical, Philosophical, and Methodological Concepts Addressed in Two Major American Art Education Publications from 1948 Through 1988 Nanette M. Carli
}

\author{
Introduction
}

Dating from the mid-twentieth century to the present time, the history of art education has not been well documented in journal articles or in texts which indicated a need for a comprehensive study aimed at the identification of concept patterns and trends. According to Barkan (1958), "An historical perspective is always necessary, because awareness of when and why many current and prevailing ideas came into being sharpens our sensitivity to the current signs and signals of changes which are now in process. Recently, there seems to have been a fragmentation in art education belief systems. It has been this "schismogenesis," the breaking apart and restructuring of art education beliefs and methods as outlined by Lanier (1963), that generated the basis for this investigation. By focusing on concept patterns and trends, it was felt that practicing art teachers could gain a broader perspective on the past and relate it to prevalent belief systems. However, an examination of available sources in art education contained limited information relative to concept patterns and trends in the past 41 years.

A variety of sources was consulted to identify and define a need for this study. Among the texts that have been widely used in the study of art education were: Logan's (1955), Growth of Art in American Schools, Belshe's (unpublished doctoral dissertation, 1947), A History of Art Education in the Public Schools in the United States, and Wygant's (1986), Art Education in the Nineteenth Century. The most common journals include Journal of Art Education and Studies in Art Education. Numerous recognized authors and researchers have identified a need for historical insight in understanding education today. Carr (1965) believes: "The past is intelligible to us only in the light of the present; and we can fully understand the present only in the light of the past." Support for historical research of conceptual development was substantiated by two senior researchers that presented at the Pennsylvania State Conference on the History of Art Education (October, 1989). Presenting at the conference, Eisner and Efland emphasized the importance of focusing historical research on understanding, identifying parallels, and relating the findings of the past to present issues in art education. Efland further stressed that :

To do this requires that we organize our understanding of the past into patterns, enabling us to see similarities between the issues that arose then with those of the present, for though 
history does not repeat itself, we are inclined to make comparisons. ... .

Eisner (1989) affirmed the process of selecting, categorizing, and analyzing specific concepts found in articles from professional art education journals as a framework to aid in the understanding of art education today.

By making connections to the past, this study was intended to compensate for the present omission of this type of historical research in the literature. The study also examined the historical chronology of the development of theoretical, philosophical, and methodological art education concepts. Hamblen (1984) maintains that "Through the reporting of history, whether in chart format or in discursive essay, relationships are revealed, patterns appear, and influences become evident." Keel (1962) also noted, "Although there may be some value in further efforts to reinterpret the general history of art education, the main opportunities lie in the domain of specialized studies, in the pursuit of institutional, biographical, topical, and local problems" (p. 47).

This investigation was concerned with identifying and categorizing specific trends of conceptual development in art education from 1948 through 1988. Chipley (1978) identified and used ten key concepts of 22 originally identified in the art education literature from 1965 through 1975. Those concepts were applied in relation to art materials used by 12 state art education coordinators (randomly chosen) from a 50 -state survey. The ten concepts identified by Chipley were: aesthetic education, interrelated arts, unified arts, perceptual awareness/visual literacy, environmental/ecology design, education of exceptional children, art education of culturally different children, humanistic education, community resource utilization, and conceptbased programs of education. The substance of nine of these concepts was used for this study. A review of the Chipley study and articles in Art Education and Studies in Art Education over the past 40 years yielded the following concepts: creativity, aesthetic education, environmental influences/ecology, humanities education, integrated activities/interdisciplinary approach, art for special needs, sensory perception, evaluation, emergent trends, and multi-cultural education. Several of Chipley's earlier categories were deleted or replaced by concepts which appeared more frequently in contemporary studies. The concept of evaluation replaced "community resource utilization" because it seemed to be more closely associated to state art education programs than with key concepts that are identifiable in practice of art education. Creativity was substituted for the broader "concept-based programs in education" category and emergent trends was used in place of "unified art" since it was closely related to integrated activities.

The major national journals considered as possible data sources for this investigation included: Art Education, Studies in Art Education, School Arts, Journal of Aesthetic Education, Review of Research in Visual Arts

Working Papers in Art Education 1991 
Education/Review of Research in Visual and Environmental Education/ Visual Arts Research, and Design for Arts in Education. Some of these journals, however, did not include writing of a theoretical or philosophical nature or were not published within the time period identified for this study.

Of the eight national journals surveyed for this study, Art Education and Studies in Art Education were selected for their status as major journals of art education and significant data sources. Hamblen (1988) affirms that these journals provide a "continuous, stable source for analysis." The art education concepts were charted to delineate the development of historical perspectives as indicated in the research journals, Art Education and Studies in Art Education, both of which are published by the National Art Education Association. According to Hamblen (1988), "Encyclopedic fact gathering, surveys, historical overviews, and record compilations are essential in establishing a sound data base."

\section{Procedures}

The investigator's initial curiosity concerning art education trends led to a charting of the articles contained in Art Education by title. Through examination of these articles, it became evident that many titles were not clearly descriptive of the actual content of the articles. Therefore, the charts, as organized by title, were not considered to be reliable research tools. However, the possibility of identifiable trends in specific content areas suggested a need for a system of identification of major art education concepts which could be used to analyze and classify the writings and research included in this study. A review of Dissertation Abstracts International provided evidence that there was an absence of dissertation research concerning specific American art education concepts for grades kindergarten through twelve for the years 1948 through 1988. Ten theoretical, philosophical, and methodological concepts were used to chart, codify, and analyze the content of relevant articles in two major art education journals, Art Education and Studies in Art Education. The key concepts and related subcategories were used as descriptors for identification of the content of pertinent articles. Concept "refers to a descriptive general term used to label an idea frequently proposed and/or discussed in art education literature to improve some aspect(s) of art education" (Chipley, 1978).

The study included only those articles that pertained to art education in the United States, kindergarten through the twelfth grade. A concept chart was developed to represent the "ebb and flow" of trends within the specified time span, using the following descriptors: 


$\begin{array}{rll}\text { Categories: } & 1 & \text { Aesthetic Education } \\ 2 & \text { Art for Special Needs } \\ 3 & \text { Creativity } \\ 4 & \text { Environmental Influences/Ecology } \\ 5 & \text { Evaluation } \\ 6 & \text { Humanistic Education } \\ 7 & \text { Integrated Activities/Interdisciplinary Approach } \\ 8 & \text { Multicultural Education } \\ 9 & \text { Sensory Perception } \\ 10 & \text { Emergent Trends }\end{array}$

The identified descriptors and the related subcategories were cited in the Thesaurus of ERIC Descriptors and the Education Index. These sources, chosen for their internal validity and acceptance as major indexes in the field of education, were further confirmed by Lee Stout, archivist at The Pennsylvania State University (personal interview, The Pennsylvania State Conference on the History of Art Education, October, 1989).

The selected concepts were not believed to be autonomous and mutually exclusive. Frequent overlap was expected due to interchangeable phrasing within the categories and subcategories. Therefore articles may have been categorized under more than one concept.

An Education Resource Index Center computer search was used to identify relevant articles from 1970 through 1988. References from Education Index were used to locate articles appearing prior to the operation of ERIC, including articles published between July 1961 and 1968, when the two journals were first included in the Education Index. To reduce researcher bias, contributing articles appearing before July of 1961 were selected and categorized by the researcher and a panel of 22 art educators who comprised a pool of independent raters for the investigation. The art educators comprising the panel of raters were chosen for their teaching experience and educational level. Each rater had a Masters or a Doctorate in the field of art education and/or a minimum of three years of teaching experience.

The articles to be rated and classified were randomly assigned to the raters from the total number of articles published in the two selected journals from September/October 1948 through June of 1961. Each rater received up to 25 articles for categorization. The investigator was aware that consistency of assignment to categories was dependent upon the objectivity of the individual juror. Hamblen (1984) asserted that:

Sinister intentions need not be present; however wellintentioned and conscientious the research may be, within the very nature of historical study a distortion occurs. ... There is no one history that is the past; rather history is a collection of perspectives consisting of selections and interpretations.

\section{Working Papers in Art Education 1991}


Articles for the study were those chosen by the respective editorial boards of each journal. Deleted from the readings were editorials, book reviews, research reviews, advertisements, convention, and membership news in order to decrease their influence on the raters.

Jurors' ratings were summarized by year and frequency within the concept categories. Data were examined from 1948 through 1988 to identify periods of time when specific concept trends occurred. The Excel computer program was used to chart possible trends in the descriptors as used by the raters and as found in ERIC and the Education Index.

Segregating the data into decades indicates the emphasis of the ten concepts within those time frames.

\section{Concept Frequency Distribution Table of Categories by Decade}

\begin{tabular}{lcccccccccccc}
\hline 1 & Decade & CAT1 & CAT2 & CAT3 & CAT4 & CAT5 & CAT6 & CAT7 & CAT8 & CAT9 & CAT10 \\
\hline 2 & 1 & 46 & 20 & 53 & 16 & 41 & 42 & 37 & 23 & 17 & 58 \\
3 & 2 & 68 & 60 & 55 & 10 & 75 & 38 & 47 & 17 & 27 & 105 \\
4 & 3 & 60 & 26 & 12 & 23 & 76 & 14 & 29 & 15 & 30 & 47 \\
5 & 4 & 125 & 50 & 9 & 5 & 41 & 6 & 24 & 10 & 39 & 75 \\
\hline
\end{tabular}

The distribution of the data identifies decades when greater or fewer articles were submitted in relation to the categories. Consistency within categories and the frequency of concepts in the articles from 1948 through 1988 becomes apparent in the decade table. In decade one, 1948-1958, categories $1,3,5,6$, and 10 received the most attention with 40 or more articles citing those concepts. Categories $2,4,7,8$, and 9 appeared in the literature 23 times or less in decade one.

Articles in categories $1,2,3,5$, and 10 had the highest frequency in the journals for decade two, 1959-1968, with 50 or more references. Those mentioned fewer than 50 times were categories 4, 6, 7, 8, and 9. Those in category 4, environmental influences/ecology, received the least attention in decade two with only 10 evident citations. 
Figures

The following four figures represent the distribution of the categories for each decade. The vertical axis numbers will vary according to the highest number of articles in each decade array. Figure 1 illustrates the first decade, 1948 through 1959.

The distribution of each category from 1948 through 1959 illustrates the frequency of inclusion for the two journals studied. All categories are represented in the journals with 16 or more categories represented across the decades. Categories $1,3,5,6,7$, and 10 were recognized in 37 or more articles. The remaining categories show no more than 23 citings. Categories 1,3 , and 10 were referred to most often. Consistency was observed between categories 5, 6, and 7 with 37 to 42 references. Between categories 2, 4, 8, and 9, from 16 to 23 occurrences were found. Figure 2 represents the second decade, 1959 through 1968. The highest frequency of concept inclusion in the journals in all four decades, 105 references, was in category 10, emergent trends.

The first three categories displayed a degree of consistency with 68 , 60 , and 55 articles concerning aesthetic education, art for special needs, and creativity. Categories 6 and 7 have also remained more consistent in this decade with 38 and 47 articles. More attention was given in 75 articles to category 5 , evaluation. The fewest concepts and correlative subdescriptors were in categories 4, 8, and 9. The third decade, 1969 through 1978, is illustrated in Figure 3. Category 5, evaluation, received the highest frequency of attention in 76 articles.

The most consistency across decade three was observed between categories 2, 4, 7, and 9. The number of articles in these categories range from 23 through 30 . Twelve, 14, and 15 articles were found in categories 3,6 , and 8 illustrating relative consistency. Categories 1 and 10 received the highest attention in this decade having been the subject of 60 and 47 articles. Figure 4 shows the fourth decade, 1978 through 1988, showing the greatest emphasis placed on category 1 . One hundred twenty-five articles were found on aesthetic education.

The highest frequency of articles in relation to emergent trends was observed from 1984 and 1985 with 16 articles each year. This concept was emphasized in 1958-1961, 1965-1966, 1976, 1984-1985, with no fewer than 11 articles. The greatest resurgence showed a growth in articles from two in 1975 to 13 in 1976. No mention of emergent trends nor related subdescriptors was found in the journals in 1970 and 1979. Fifteen of the 41 years exhibited five or fewer articles. The mean score for this category was 6.95 .

Working Papers in Art Education 1991 
Figures

The following four figures represent the distribution of the categories for each decade. The vertical axis numbers will vary according to the highest number of articles in each decade array. Figure 1 illustrates the first decade, 1948 through 1959.

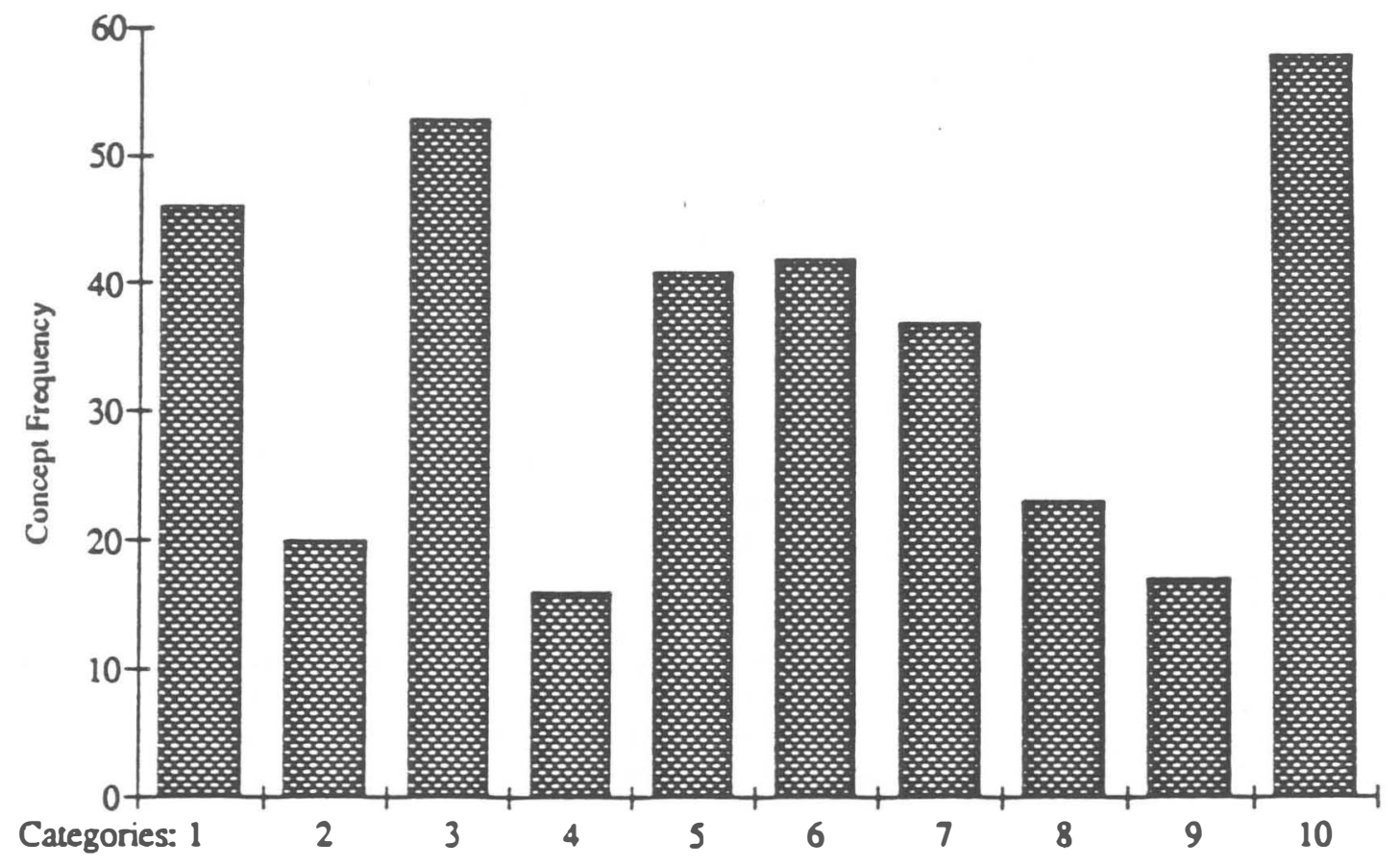

Figure 1. Decade Chart 1, Categories 1 - 10, 1948 - 1958 
The distribution of each category from 1948 through 1959 illustrates the frequency of inclusion for the two journals studied. All categories are represented in the journals with 16 or more categories represented across the decades. Categories $1,3,5,6,7$, and 10 were recognized in 37 or more articles. The remaining categories show no more than 23 citings. Categories 1,3 , and 10 were referred to most often. Consistency was observed between categories 5, 6, and 7 with 37 to 42 references. Between categories 2, 4, 8 , and 9, from 16 to 23 occurrences were found. Figure 2 represents the second decade, 1959 through 1968. The highest frequency of concept inclusion in the journals in all four decades, 105 references, was in category 10, emergent trends.

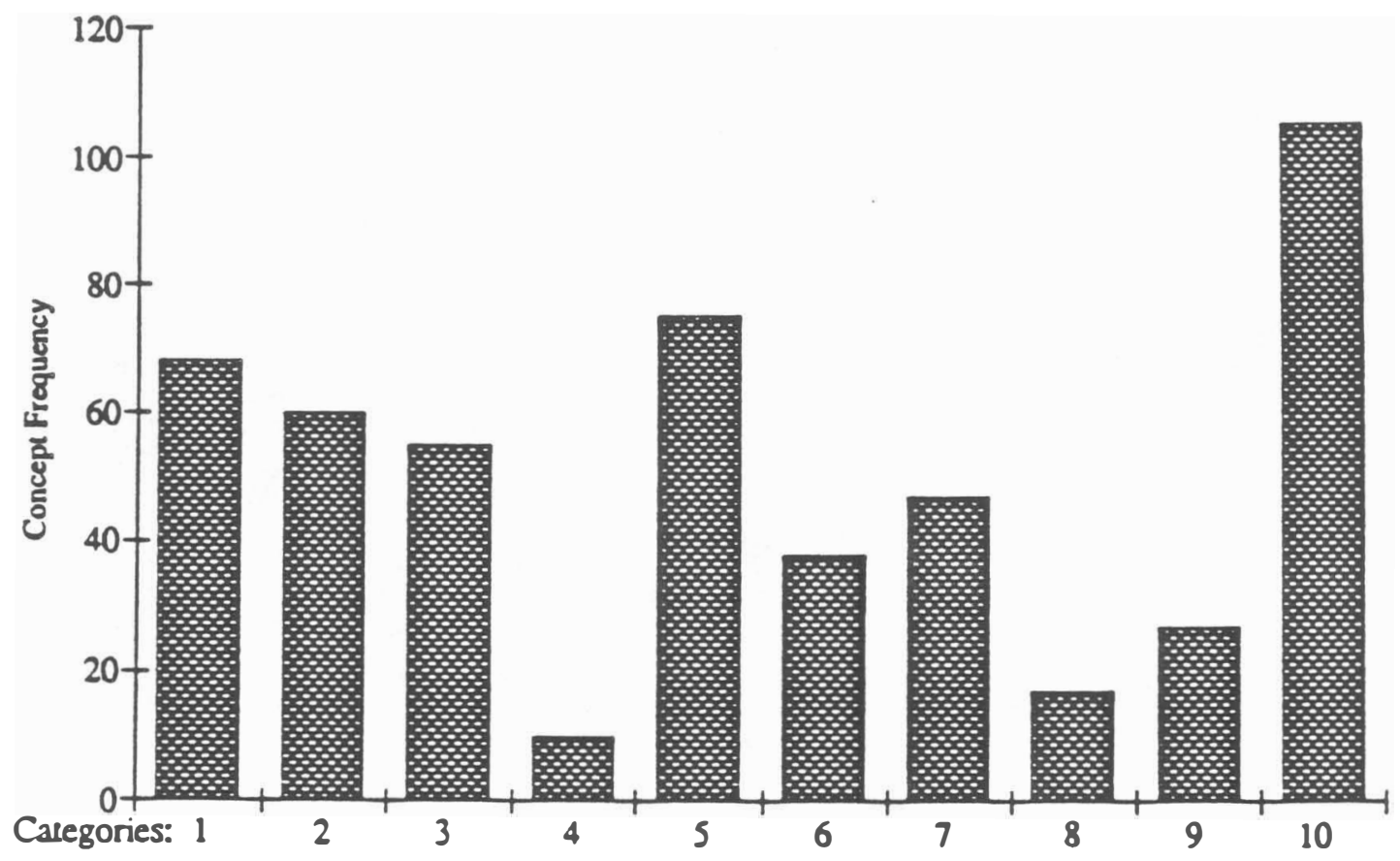

Figure 2. Decade Chart 2, Categories 1 - 10, 1959- 1968 
The first three categories displayed a degree of consistency with 68 , 60 , and 55 articles concerning aesthetic education, art for special needs, and creativity. Categories 6 and 7 have also remained more consistent in this decade with 38 and 47 articles. More attention was given in 75 articles to category 5 , evaluation. The fewest concepts and correlative subdescriptors were in categories 4, 8, and 9. The third decade, 1969 through 1978, is illustrated in Figure 3. Category 5, evaluation, received the highest frequency of attention in 76 articles.

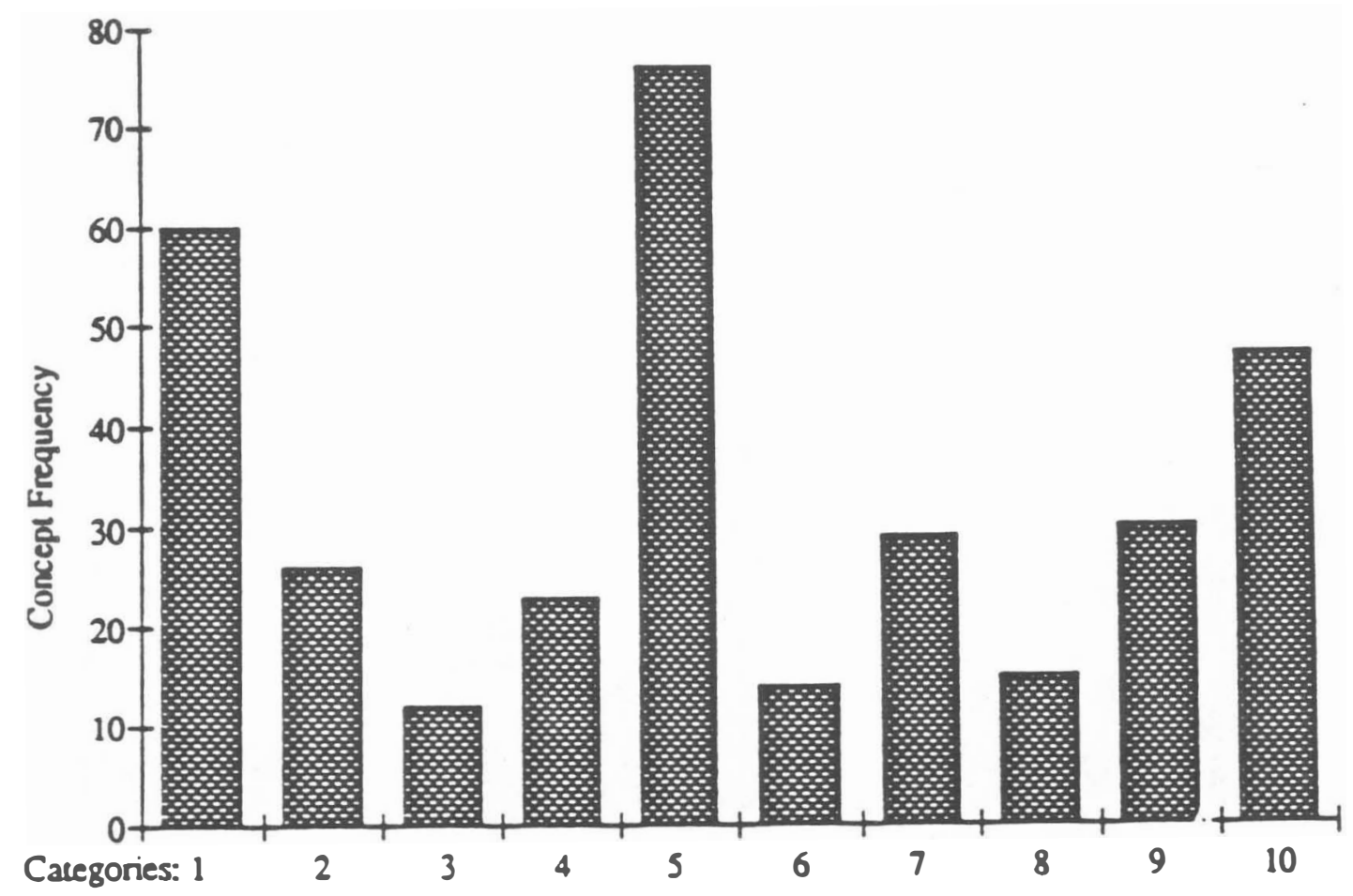

Figure 3. Decade Chart 3, Categories $1-10,1969-1978$ 
The most consistency across decade three was observed between categories 2, 4, 7, and 9. The number of articles in these categories range from 23 through 30 . Twelve, 14, and 15 articles were found in categories 3, 6, and 8 illustrating relative consistency. Categories 1 and 10 received the highest attention in this decade having been the subject of 60 and 47 articles. Figure 4 shows the fourth decade, 1978 through 1988, showing the greatest emphasis placed on category 1 . One hundred twenty-five articles were found on aesthetic education.

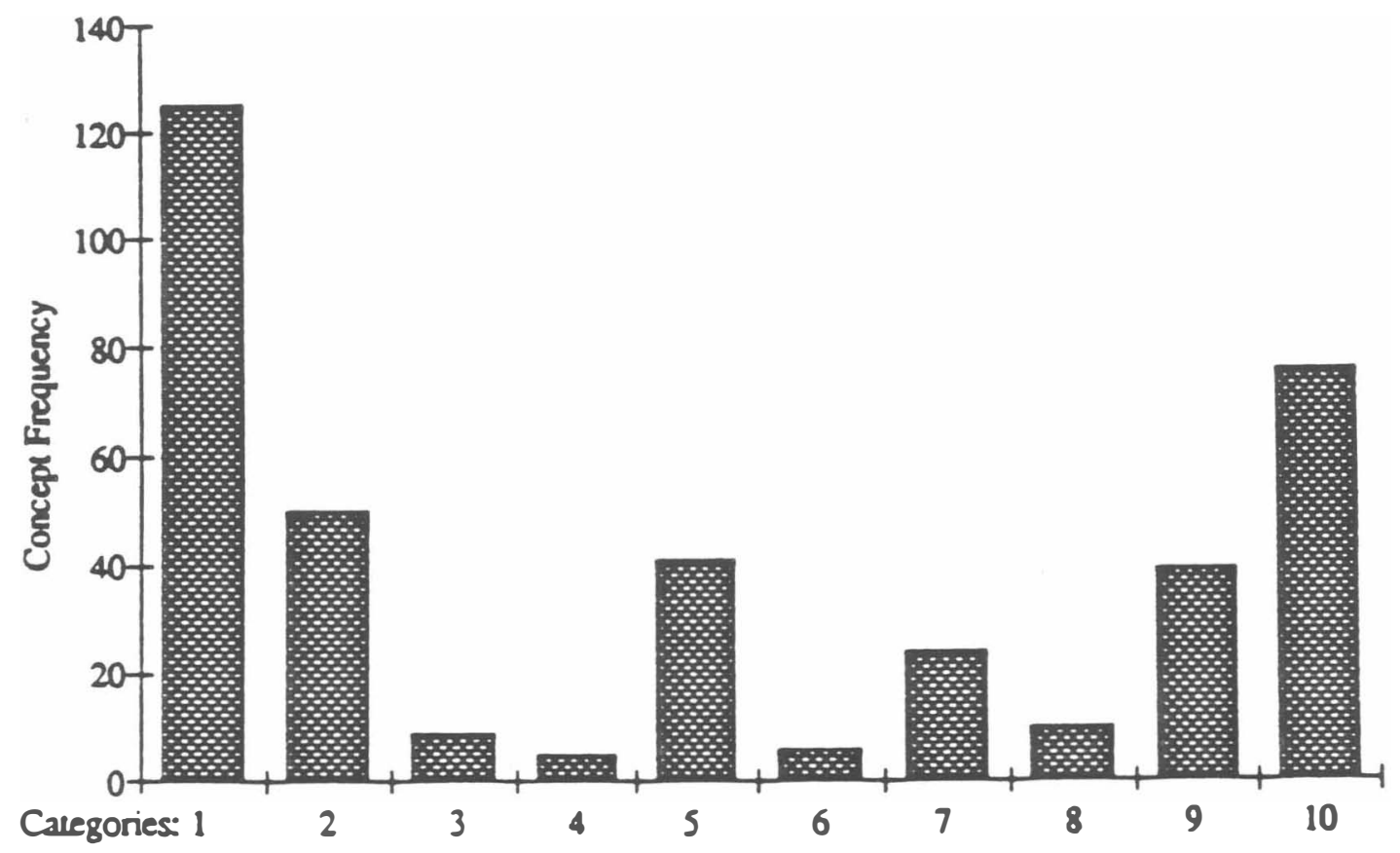

Figure 4. Decade Chart 4, Categories 1 - 10, $1979-1988$ 
The highest frequency of articles in relation to emergent trends was observed from 1984 and 1985 with 16 articles each year. This concept was emphasized in 1958-1961, 1965-1966, 1976, 1984-1985, with no fewer than 11 articles. The greatest resurgence showed a growth in articles from two in 1975 to 13 in 1976. No mention of emergent trends nor related subdescriptors was found in the journals in 1970 and 1979. Fifteen of the 41 years exhibited five or fewer articles. The mean score for this category was 6.95 .

\section{Summary}

The greatest frequency of concept inclusion in Art Education and Studies in Art Education has been observed in two of the ten categories. These two categories were aesthetic education with 299 references and emergent trends with 285 citings. The lowest frequency occurred in category 4 (1979 and 1988), environmental influences/ecology, when five references to that concept were found. A decline of concept frequency was found for creativity, environmental influences/ecology, evaluation, humanistic education, integrated activities/interdisciplinary approach, and multicultural education in the last decade studied. In the same period of time writings, in the categories of aesthetic education, art for special needs, sensory perception, and emergent trends increased in the journal articles.

Working Papers in Art Education 1991 